\title{
Iteration of Smoke Movement Simulation Processes for an Optimized Specification of Ventilation Parameters, with a View to Control Fire-Induced Smoke Flows in Atrium Buildings
}

\author{
XAVIER EMILE BODART, MICHEL ROGER CURTAT and PHILIPPE CONSTANTIN FROMY \\ Centre Scientifique et Technique du Bâtiment
}

BP 02 - 77421 Marne-la-Vallée Cedex 2, France

\begin{abstract}
This paper aims at illustrating the potential flexibility of the use of smoke movement modelling for the purpose of elaborating tables or diagrams specifying in a straightforward way minimal values of ventilation parameters such as vent areas or fan-powered flow rates, for the control of smoke flows in the case of building fires. This is particularly relevant to the case of atrium buildings since the regulatory codes in force in France have so far proved unsatisfactory for smoke control. Despite the number of parameters intervening in smoke movement processes that cannot all be controlled at design level, such an approach has the advantage of clearly highlighting theoretical assumptions, especially with regard to safety criteria. The effectiveness of a smoke control system based upon such assumptions can thus be more easily assessed. However, this may sometimes result in very high levels of ventilation rates, leading to a potential increase in implementation costs.
\end{abstract}

Keywords: $\quad$ fire, atrium, modelling, smoke, computer, design, safety, control, building, simulation, optimization, engineering

\section{INTRODUCTION}

To date in France, scientific approaches to smoke control regulations remain a rarity, and safety designers still rely on sets of tables or diagrams to determine minimal values of ventilation parameters. These tables and diagrams, included in official texts [1,10], merely give specified values to be selected for smoke vent areas or fanpowered ventilation rates, without any further computation except for rules of three or 1-D interpolations.

We have mentioned in a previous paper [2] the unsuitability of this regulatory approach for smoke control in atrium buildings, citing a number of reasons [3]. Nevertheless, various points of view exist with regard to the possibility of standardization in that field [4-7].

Recently, some attempts have been made [8,9] to obtain comprehensive information from simulation results carried out with computer models. These concerned smoke movement involving several atrium types with dimensions varying in such a way that all types of atrium may be catered for. Nonetheless, extensive studies have generally been applied only to specific cases, eg. [2,11].

In fact, computer models of smoke movement have proved helpful to assess the effectiveness concerning smoke control equipment in buildings with or without an atrium. A further step might consist in making use of computer simulation in order to design the best equipment for ensuring adequate protection against smoke in specific conditions. Restricting our ambitions, we shall now present several procedures which iterate smoke movement 
simulation with a view to optimizing ventilation parameters such as vent area or fan-powered flow rate, in cases where atrium buildings are concerned.

The CIFI computer model was used for the various simulations involved: CIFI is a multiroom model (already presented in [2] and [12]), the main features of which are: a finite volume model incorporating gas stratification in rooms; heat and mass transfer for each of the zones (gases/walls); fire plumes and doorjet entrainments calculated by means of appropriate formulae found in the literature (eg. $[13,14]$ for further information). The structural variety of configurational data does not facilitate the validation process of such a model - a long task still under development, although ClFl features rather well the main phenomena of smoke movement and control in building configurations such as those being approached in this paper.

\section{GENERAL ASSUMPTIONS, FREEZE OF PARAMETERS AND CHOICE OF SAFETY CRITERIA}

Smoke control in buildings should ideally integrate the fact that many parameters have an influence on the course of smoke movement in case of fire. In a C.S.T.B. report [14] we have identified no less than forty scalar parameters which can be divided into two groups:

- "internal" parameters, i.e. parameters governing numerical data-processing and parameters characterizing choice between various formulations available to the user(esp. with regard to calculation of entrainment rates and heat transfer coefficients);

- "external" parameters, which define the physical configuration involved in a process of fire development and smoke movement (building geometry, ventilation characteristics, detection, management of various systems, meteorological conditions - wind and temperature - and fire source characteristics).

Among the parameters involved can be distinguished those which can be more or less controlled at design level and those which cannot; it was however not possible to take into account the incidence of the variability of each parameter in the context of an optimization process commanding complex computations. Therefore we "froze" some parameters by assigning average values to them, e.g. the parameters governing the inner and outer ambient temperatures were always given values corresponding to mid-season conditions.

Furthermore, we considered the variability of atrium configurations and selected two basic schemes:

- Scheme 1: room/walkway/atrium connected to each other in this order

- Scheme 2: room/atrium (connected)

We associated three basic cases with these schemes:

- Case 1: bedroom/walkway/atrium (associated with Scheme 1)

- Case 2: commercial room/atrium (associated with Scheme 2)

- Case 3: commercial room/walkway/atrium (associated with Scheme 1)

We then assumed various possibilities for the fire source, resulting in the seven families of configurations given in Table 1.

TABLE 1

\begin{tabular}{|c|c|c|c|c|c|}
\hline $\begin{array}{c}\text { Basic } \\
\text { case }\end{array}$ & $\begin{array}{c}\text { Fire } \\
\text { room }\end{array}$ & $\begin{array}{c}\text { Fire } \\
\text { type }\end{array}$ & $\begin{array}{c}\text { Subscheme \& basic } \\
\text { scheme referred to }\end{array}$ & $\begin{array}{c}\text { Smoke exhaust near } \\
\text { ceiling of: }\end{array}$ & $\begin{array}{c}\text { Family of } \\
\text { configurations }\end{array}$ \\
\hline 1 & Bedroom & 1 & Bedroom + corridor(1) & Corridor & 1 \\
\hline 1 & Atrium & 2 & Atrium(1) & Atrium & 2 \\
\hline 2 & Room & 2 & Room(2) & Room & 3 \\
\hline 2 & Atrium & 2 & Atrium(2) & Atrium & 4 \\
\hline 3 & Room & 2 & Room(1) & Room & 5 \\
\hline 3 & Room & 2 & Room + corridor(1) & Corridor & 6 \\
\hline 3 & Atrium & 2 & Atrium(1) & Atrium & 7 \\
\hline
\end{tabular}


Table 1 needs further explanation: the fire type 1 refers to an "envelope" of data measured at C.S.T.B. [16] concerning bedding fires (with alveolar mattresses made of polyurethane foams), resulting in a fire which peaks at $2.8 \mathrm{MW}$, a value reached in $5 \mathrm{~min}$. and maintained for $4 \mathrm{~min}$; it then decreases and finally extinguishes itself $28 \mathrm{~min}$. from its outbreak. The fire type 2 is a $1-\mathrm{MW}$ wood fire with a burning area of $9 \mathrm{~m} 2$, a maximal value being reached in $5 \mathrm{~min}$.(plateau power) and then maintained in a quasi-steady state.

In addition, the relationship between basic schemes and subschemes needs to be explained; in Family 1 for instance (as it appears in Table 1), we shall detail below (Table 2) a safety criterion selected as follows: the basis of the smoky upper layer forming beneath the ceiling of the walkway (by penetration of smoke coming from the bedroom) always remains higher than 2 metres above the walkway floor. This should prevent any movement of smoke towards the atrium volume, and therefore we considered that a subscheme comprising only bedroom and walkway should be sufficient for the smoke movement simulations, the atrium itself being assimilated to the outside of such a system. Thus, the links between schemes and subschemes are motivated by the nature of the safety criteria that have been selected (see Table 2.)

TABLE 2

\begin{tabular}{|c|c|c|c|c|}
\hline $\begin{array}{l}\text { Family of } \\
\text { configurations }\end{array}$ & $\begin{array}{l}\text { Geometrical degree of } \\
\text { freedom }\end{array}$ & $\begin{array}{l}\text { Safety criterion } \\
\text { selected }\end{array}$ & Remarks & $\begin{array}{l}\text { Degree of } \\
\text { freedom } \\
\text { influencing } \\
\text { safety criterion }\end{array}$ \\
\hline 1 & none & $\begin{array}{c}\mathrm{SLBH}>=2 \mathrm{~m} \\
\text { in walkway volume }\end{array}$ & $\begin{array}{c}\text { criterion tested at any time } \\
\text { during the fire history }\end{array}$ & none \\
\hline 2 & $7<\mathrm{AH}<30$ & $\mathrm{SLBH}>=\mathrm{HIOSH}$ & $\begin{array}{c}\text { criterion tested on a limit value } \\
\text { of SLBH }\end{array}$ & HIOSH \\
\hline 3 & $\begin{array}{c}\mathrm{RFA}=100 \text { or } 200 \text { or } \\
300 \mathrm{~m} 2\end{array}$ & SLBH $>=2 \mathrm{~m}$ & $\begin{array}{l}\text { criterion tested at any time } \\
\text { during the fire history }\end{array}$ & none \\
\hline 4 & $7<\mathrm{AH}<30$ & SLBH $>=$ HIOSH & $\begin{array}{c}\text { criterion tested on a limit value } \\
\text { of SLBH }\end{array}$ & HIOSH \\
\hline 5 & $\begin{array}{c}\text { RFA }=100 \text { or } 200 \text { or } \\
300 \mathrm{~m} 2\end{array}$ & $\mathrm{SLBH}>=2 \mathrm{~m}$ & $\begin{array}{l}\text { criterion tested at any time } \\
\text { during the fire history }\end{array}$ & none \\
\hline 6 & $\begin{array}{c}\mathrm{RFA}=100 / 200 / 300 \mathrm{~m} 2 \\
\mathrm{WW}=1.4 / 3 / 6 \mathrm{~m} \\
2<=\mathrm{RWOW}<=20 \mathrm{~m}\end{array}$ & $\begin{array}{c}\text { SLBH }>=2 \mathrm{~m} \\
\text { in walkway volume }\end{array}$ & $\begin{array}{l}\text { criterion tested at any time } \\
\text { during the fire history }\end{array}$ & none \\
\hline 7 & $7<\mathrm{AH}<30$ & $\mathrm{SLBH}>=\mathrm{HIOSH}$ & $\begin{array}{c}\text { criterion tested on a limit value } \\
\text { of SLBH }\end{array}$ & HIOSH \\
\hline
\end{tabular}

SLBH = smoke layer basis height

$\mathrm{AH}=$ atrium height

HIOSH $=$ highest internal opening soffit height

RFA $=$ room floor area

$\mathrm{WW}=$ walkway width

RWOW = room/walkway opening width

Further information is also needed to understand this table. Starting with the 1st family of configurations, where a bedroom is connected to a corridor, without geometrical degree of freedom in it, it should be understood that the corresponding parameters are"frozen" (see next Section for details).

In addition, the results provided by a procedure automating simulation of smoke movement consist of minimal values of smoke exhaust area for "natural" exhaust systems (i.e. smoke movement governed primarily by buoyancy), minimal values of volume flow rate of smoke exhaust for fan-powered systems. Moreover, the air supply areas must be large enough, i.e. at least equivalent to the exhaust areas provided when natural ventilation is selected.

Coming back to the 1 st family, the safety criterion is satisfied as long as the bottom of smoke layer in the walkway volume remains higher than 2 metres. This criterion is fixed, which means therefore that the 1st family of configurations includes one element only, and the automation procedure should then lead to a single optimized value of minimal exhaust area (resp. volume flow rate) in the case of natural (resp. mechanical) ventilation. Conversely, the most complex family with respect to its geometrical degree of freedom is the sixth one: the room 
floor area, like the walkway width, may receive three values, and moreover the width of the room/walkway opening can vary from 2 to 20 metres.

As to the safety criteria we selected, it is very important to notice that in some cases some conditions must be met at any time during the fire while in other cases some conditions must be met after a certain duration of time sufficient for ambient conditions to become quasi-steady; the former cases correspond to a fire source outside the atrium volume (in which case any flow of smoke towards the atrium volume should be avoided), the latter cases correspond to an atrium fire (in which case the safety requirement is reduced because of the difficulty of ensuring an adequate level of smoke control).

The following Sections detail some of the automation procedures resulting from the above, chosen as representative of various types of problems that we had to cope with. They were written in VMS-command language and implemented on a VAX/VMS 11-780 computer. The results that these procedures led to are subsequently discussed.

\section{IST FAMILY: SINGLE OPTIMIZATION OF EXHAUST PARAMETER IN A BEDROOM + WALKWAY CONTEXT}

It was stated in the previous Section that the 1st family includes a single bedroom + walkway configuration, as many parameters are "frozen". The following are details concerning the generic configuration:

- a bedroom of $5 \mathrm{~m} \mathrm{x} 4 \mathrm{~m} \times 2.50 \mathrm{~m}$ in height

- a walkway of $30 \mathrm{~m} \times 1.40 \mathrm{~m} \times 2.50 \mathrm{~m}$ in height

- a bedroom/walkway door (height of $2 \mathrm{~m}$; width of $0.90 \mathrm{~m}$ )

- a walkway/outside door (height of $2 \mathrm{~m}$; width unknown)

- a smoke exhaust with mouth located at walkway ceiling (area unknown in natural ventilation/volume flow rate unknown in mechanical ventilation)

- ambient temperature before fire outbreak: $20 \mathrm{C}$ everywhere

- no wind

- walls made of a low-conductivity material (0.13 S.I.)

- convective heat transfer coefficient $=10$. S.I.

- calculation of air entrainment into the flame plume: Thomas' formulae [12]

- fan-powered exhaust ventilation, if any, starts $30 \mathrm{sec}$. after fire outbreak

A first automation procedure aimed at determining the minimal value of smoke exhaust area in natural ventilation, and $1.08 \mathrm{~m} 2$ was found for a series of cases where the same value was considered for the smoke exhaust area and air inlet area (from and to walkway). Rather than detailing further this procedure, we shall focus on a second procedure aiming at the determination of the minimal value of volume flow rate in fan-powered ventilation: this second procedure is in all respects very similar to the first, having also just one unknown to be optimized. In the case of the second procedure, $1.08 \mathrm{~m} 2$ was used for air inlet area.

Flow chart 1 gives the successive commands of the second automation procedure. Non-standard elements appear: hexagons (referring to data files, or result files, or software files) and broken curved lines with arrows, which link a command or a test with the files mentioned (two opposite arrows mean that a file is "killed", i.e. destroyed).

We can now follow the chart's commands from the "beginning":

- choice of an initial span of volume flow rates of smoke exhaust $\left(x_{1}, \times 2\right)$. $\times 1$ should be small in such a way that the lower part of the walkway volume is unprotected from smoke-logging at a moment or another during the fire, the flow rate of smoke exhaust from the upper part of the walkway volume being $x 1$ (in S.I. units). Conversely, $\mathrm{x} 2$ should be big enough to ensure an adequate protection of the walkway. The procedure firstly aims at determining the smallest $\mathrm{x}$ between $\mathrm{x} 1$ and $\mathrm{x} 2$ ensuring the minimal smoke protection still adequate. However,the initial values of $x 1$ and $x 2$ may not meet the above-mentioned criteria, in which case the 1 st stage of the procedure alters $\left(\mathrm{x}_{1}, \mathrm{x} 2\right)$.

- creation of a simulation command file with the current value $\mathrm{x}$ of smoke flow rate, set initially to $\mathrm{x} 1$ with a minus sign meaning that it corresponds to an exhaust rate). This file is FICOM and executes CIFI when executed itself (see the oriented link with the CIFI-hexagon);

- execution of the FICOM file, i.e. performance of a computer simulation with CIFI, which feeds a file of results FIRES; 


\section{FLOW CHART 1}

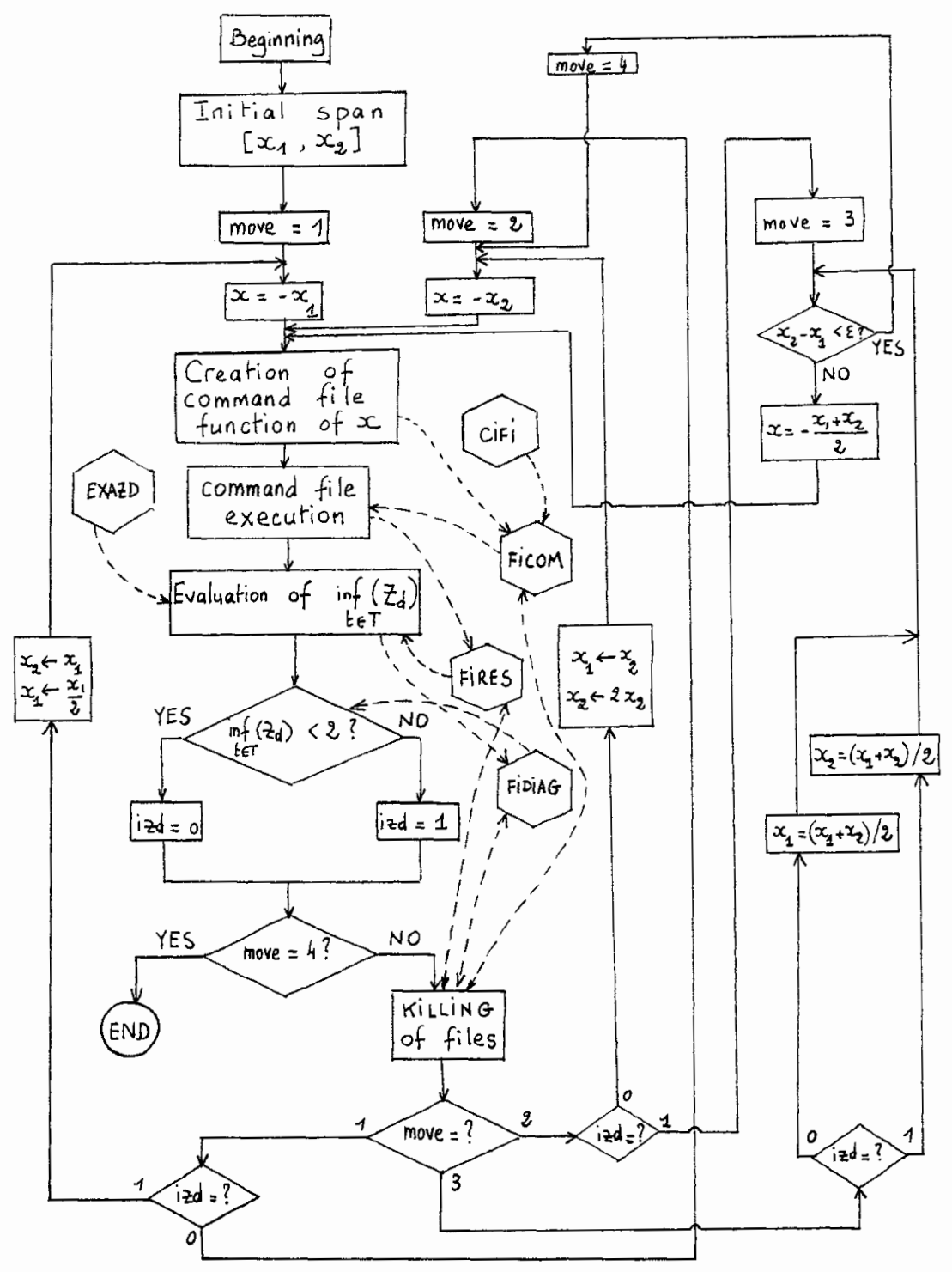


- evaluation of $\min (\mathrm{Zd})$ over $\mathrm{T}(\mathrm{T}=$ duration of fire), $\mathrm{Zd}$ being the height of the smoke-free zone in the walkway calculated in the above-mentioned simulation: this task just consists of a search in FIRES;

- test traducing a safety criterion: if the value $\min (\mathrm{Zd})$ is smaller than 2 (in metres) this criterion is not met, and conversely. It is thus assumed that the smoke control system is satisfactory if it can exhaust smoke progressively in such a way that a height of 2 metres in the walkway volume remains always protected from logging of the smoke which flows from the room during the fire. This test uses an intermediate file FIDIAG;

- the parameters "izd" and "move" are used for procedure control: izd is set to 1 if the above-mentioned safety criterion is met, 0 otherwise;

- destruction ("killing") of various files (see arrows)

- test on izd: if 1 , the current value of $x 1$ is not small enough and has to be reduced and a simulation command file creation an execution restarted. Conversely, as soon as izd can be set to 0 , the procedure begins to perform a series of checks on $x 2$ with CIFI simulations and modifies $x 2$ if necessary. All these operations, when performed, result in a modification of the initial span $(\mathrm{x} 1, \mathrm{x} 2)$;

- the aforementioned steps of the procedure use extensively the control parameters "move" and "izd". They are

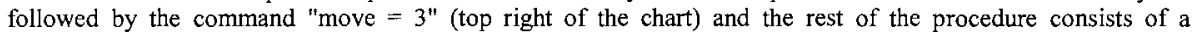
dichotomy: the span $(\mathrm{x} 1, \mathrm{x} 2)$ is progressively narrowed until $\mathrm{x} 1$ differs from $\mathrm{x} 2$ by less than an "epsilon". The procedure then executes the command "move $=4$ ", followed by an ultimate simulation using the "solution" $\mathrm{x} 2$ without subsequent file killing, since it is desirable to keep track of its results).

The second iteration procedure led to the optimal value of $3.32 \mathrm{~m} 3 / \mathrm{sec}$. after the automation of less than $20 \mathrm{CIFI}$ simulations.

\section{ND FAMILY: ATRIUM VOLUME CONTEXT}

The following are details concerning the generic configurations:

- an atrium of $10 \mathrm{~m} \times 10 \mathrm{~m} \mathrm{x}$ " $h " \mathrm{~m}$ in height ( $\mathrm{h}$ is the parameter "A.H." of Table 2 , with $7<=h<=30 \mathrm{~m}$ );

- a smoke exhaust located at ceiling (its area is unknown);

- a door on the outside (height of $2 \mathrm{~m}$, width unknown but linked with the unknown area of the smoke exhaust see below).

A first automation procedure calculated values of smoke-free zone height obtained with natural smoke exhaust considering smoke exhaust area and air supply area the same parameter, and the door width accordingly (air was supplied through that door). As stated in a previous section, the fire source was assumed to be quasi-steady and internal walls to be not very conductive. Consequently, the choice of an - apparently arbitrary - small floor area was made in such a way that quasi-steady smoke logging conditions were reached some 20 minutes after fire outbreak, and the following paragraph explains why these conditions are independent of the atrium floor area. The procedure then leaded to a set of curves: each choice of an atrium height (in the range $7-30 \mathrm{~m}$ with a halfmetre step) resulted in a curve gathering points corresponding to various limits of smoke exhaust rates calculated by CIFI-simulations. These curves were then slightly smoothed and plotted on Figure 1, which could be translated if necessary into a table of numbers by means of any convenient interpolation technique.

A second procedure just aimed at using the previous results to present the variations of smoke-free heights versus limits of smoke exhaust flow rate. As expected, the 47 curves (one for each atrium height, in the range 7-30m with a step of $0.5 \mathrm{~m}$ ) overlap (see Figure 2). This can be explained as follows: when a limit of smoke exhaust flow rate is reached, it balances the global fire plume rate which fills the smoke layer beneath the ceiling; that plume rate is directly linked to the height of the smoke-free zone, independently of the atrium height; also, for a same limit of smoke exhaust flow rate, the limit temperature of the smoke layer varies very little versus atrium height as well as versus floor area, since transfer terms due to mass transport are much bigger in energy balance of hot layer than those due to heat losses to zone walls; consequently, a limit of smoke exhaust mass flow rate corresponds to a single value for the limit of smoke exhaust volume flow rate.

Both procedures resulted however in rather high values of smoke exhaust parameters: e.g. to keep a smoke-clear zone $10-\mathrm{m}$ high, the minimal value of $100 \mathrm{~m} 3 / \mathrm{sec}$. was obtained whatever atrium height, corresponding for instance to a value of $100 \mathrm{~m} 2$ of exhaust area in natural ventilation for an overall height of 13 metres. This recalls us, alas, the well-known difficulty of establishing an efficient smoke control whenever an atrium is concerned and a fire develops in the atrium volume. 
FIGURE 1

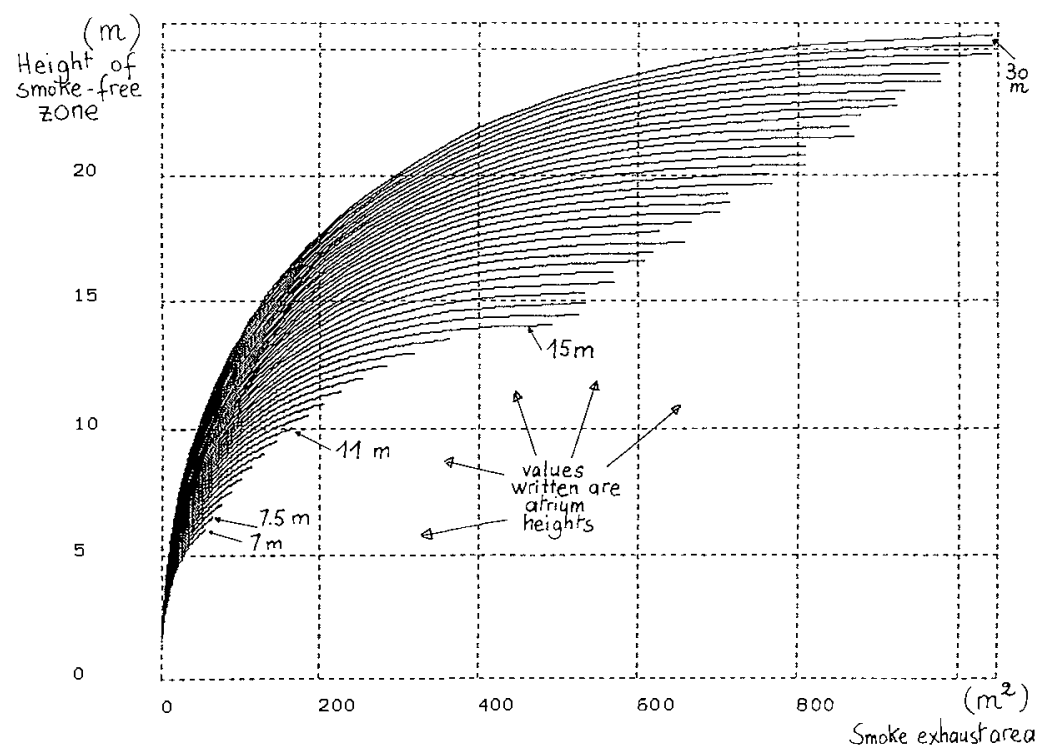

\section{FIGURE 2}

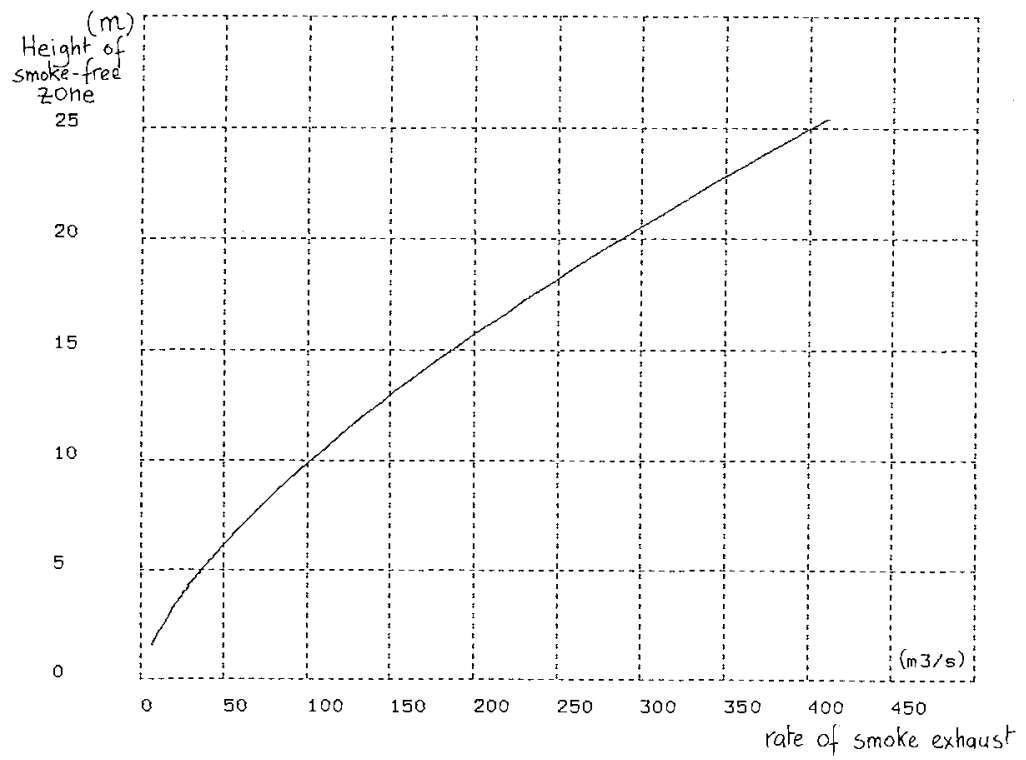




\section{TH FAMILY: COMMERCIAL ROOM + WALKWAY CONTEXT}

The two procedures involved here (the former assuming natural ventilation for smoke exhaust, unlike the latter) differ from those of the Ist family as follows (see Table 2):

- the fire source is not the same type

- the floor area of the room can be given three values

- the walkway width can also be given three values

- the room/walkway door width ranges from 2 to $20 \mathrm{~m}$

Flow chart 2 resulting from those assumptions is therefore more complex because it manipulates various additional command and data files. It nevertheless embeds a dichotomy process very similar to that of Flow chart 1 (note that Flow chart 2 is related to the procedure of optimization in natural ventilation, unlike Flow chart 1 designed for fan-powered ventilation).

Each procedure led to results which were slightly smoothed and then plotted on Figure 3 (resp. 4) corresponding to natural (resp. mechanical) ventilation. Both figures gather 3 groups of three curves (solid $/$ short-dashed/longdashed), and each curve is referenced by a number from 1 to 9 , referring to a configuration as shown in Table 3 . These procedures needed a CPU time of the order of magnitude of a day of computation on a VAX-VMS $11 / 780$ computer.

TABLE 3

\begin{tabular}{|l|c|c|c|c|}
\hline$\downarrow$ Walkway width(m) & 100 & 200 & 300 & 6Room area $(\mathrm{m} 2)$ \\
\hline 1.4 & 1 & 2 & 3 & \\
\hline 3 & 4 & 5 & 6 \\
\hline 6 & 7 & 8 & 9 \\
\hline
\end{tabular}

\section{FIGURE 3}

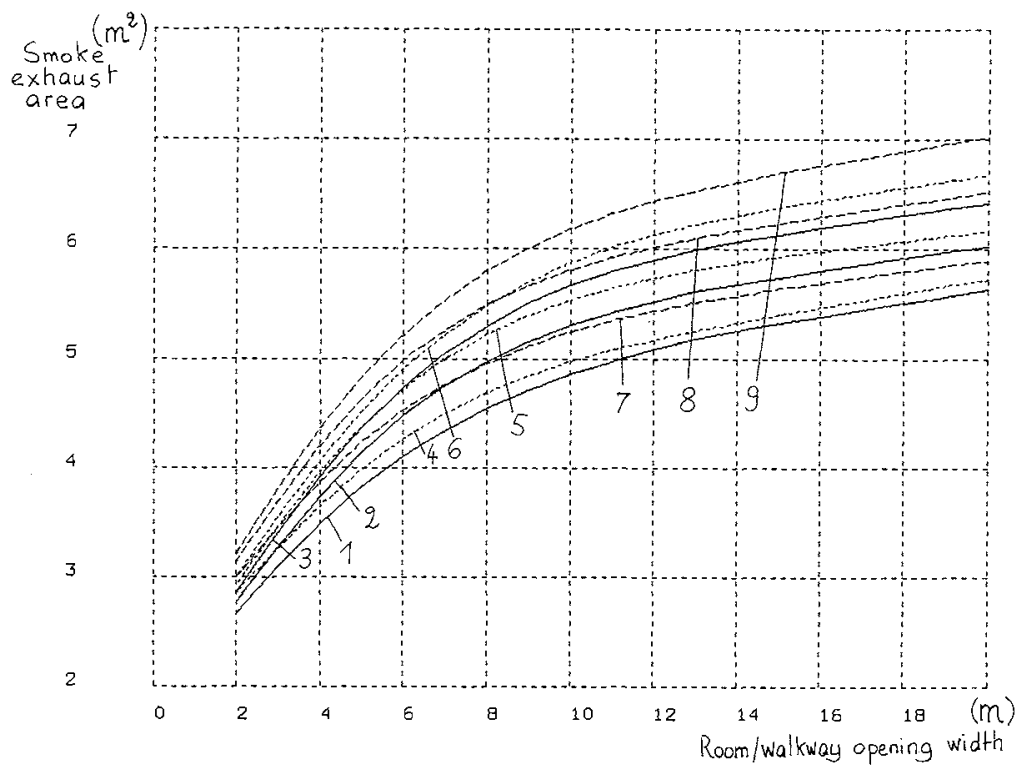




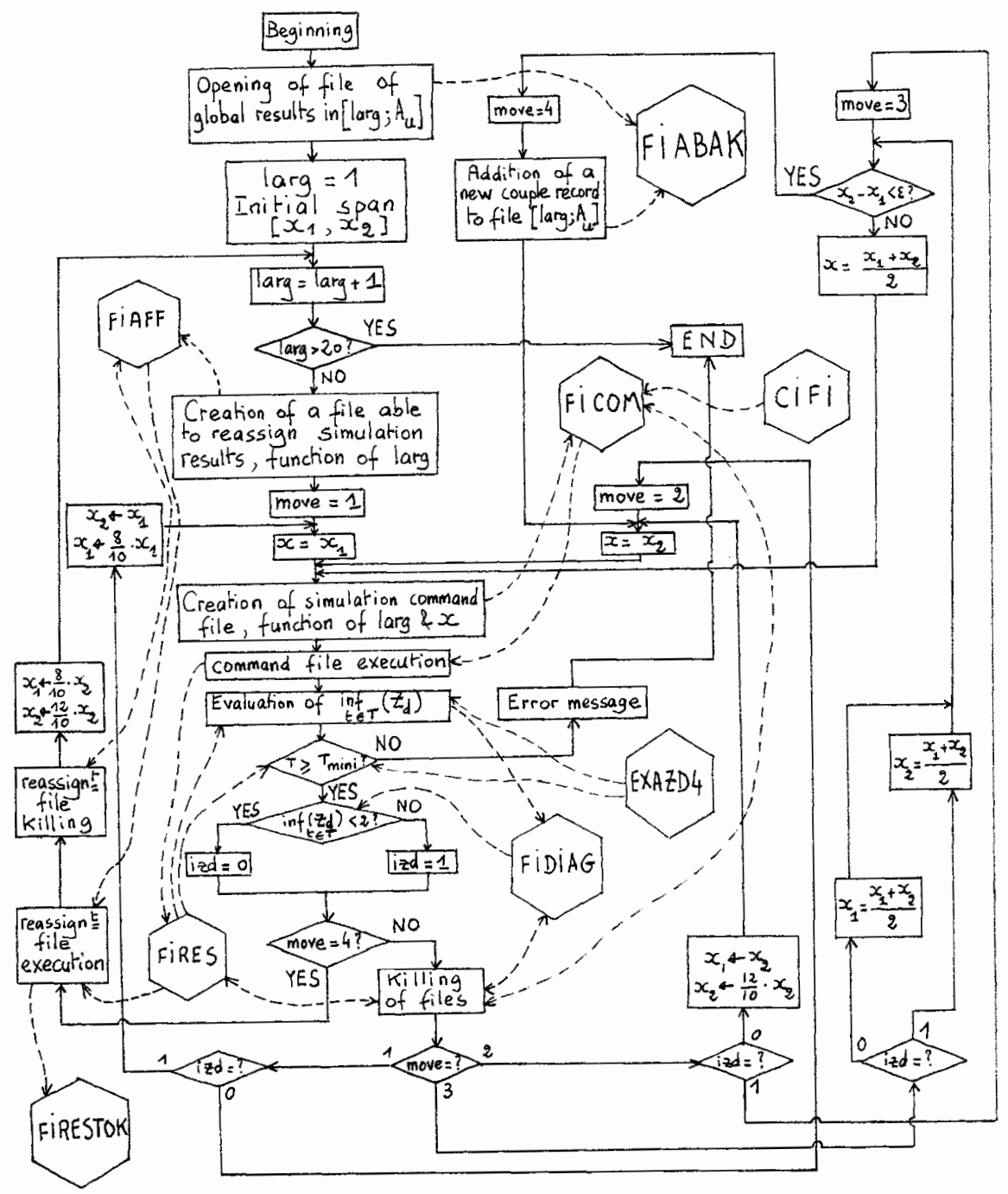




\section{FIGURE 4}

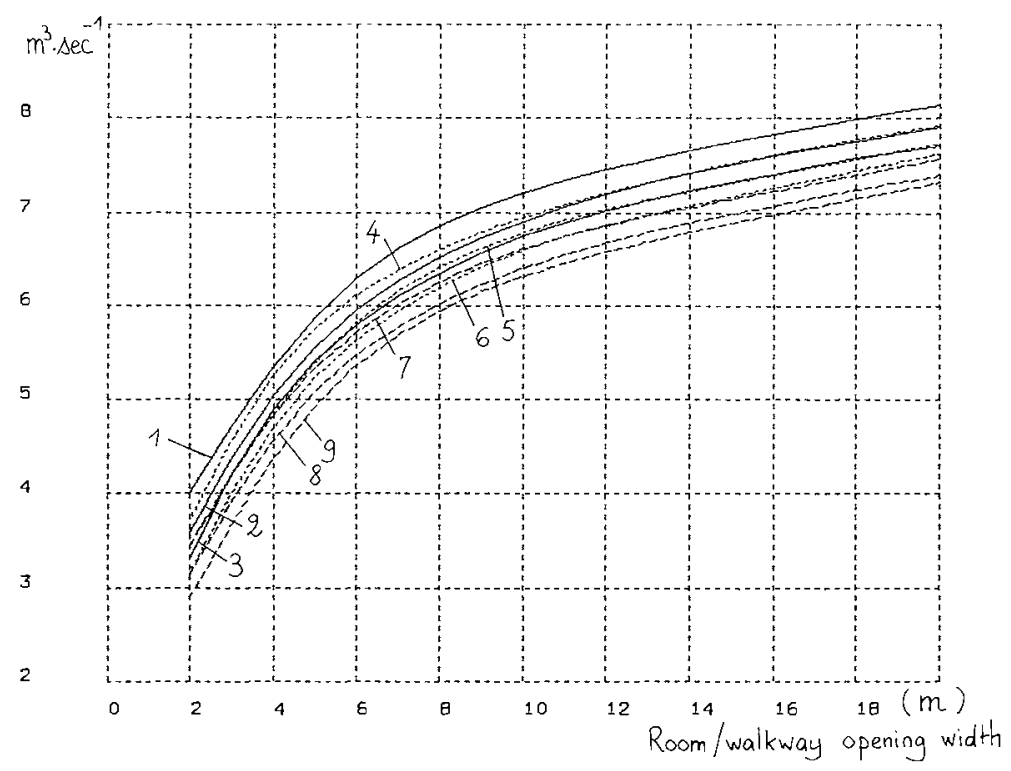

A general trend: the optimized exhaust rate or area increases with the room/walkway door width, and therefore with the area since the door height is constant. In other respects, the optimized exhaust area increases with the floor area of room because the average temperatures decrease. More precisely the history as a function of time of the mean temperatures of the walkway smoke layer follow a curve located lower for a larger room, and therefore the buoyancy-powered ventilation is weaker. Consequently and conversely, the optimized exhaust flow rate decreases with the floor area of room because a volume flow rate corresponds to a higher mass flow rate for a lower flow temperature since gas density is higher. For similar reasons, the optimized exhaust areas increase with the walkway width, unlike the optimized exhaust flow rates.

\section{CONCLUSION}

The present paper has tried to illustrate that a multiroom model of simulation of smoke movement in the case of building fire (namely CIFI, the C.S.T.B. 2-zone model) can be used to determine in a straightforward way optimized ventilation coefficients for geometries and conditions with a practical application to the existing and future atrium buildings, albeit in a simplified and non-exhaustive manner. This has enabled us to elaborate simple diagrams which may be used to complement existing but rather unsatisfactory means of dealing with the problem of smoke control in atria.

The fact that systemic effects accompanying fire and smoke development and movement are dealt with, constitutes an improvement. These optimization techniques are now easily implementable as data-processing is becoming faster with today 's minicomputers. However, although these techniques may sometimes lead to perhaps unrealistic ventilation characteristics, especially when the question is the control of smoke logging resulting from an atrium fire, their essential advantage lies in a clear statement of the basic assumptions, and therefore a clear view of the objectives and limits assigned to the procedures. This enables the designer to evaluate the degree of effectiveness and reliability of ventilation systems resulting from their application in the real world. 


\section{ACKNOWLEDGMENTS}

We are especially indebted to the Ministry of Research and to the "Direction de la Sécurité civile" of the French Ministry of the Interior for having facilitated the elaboration of approaches such as those commented in the present document.

\section{REFERENCES}

1. Règlement de sécurité contre l'Incendie relatif aux Etablissements recevant du public..., edited by France Sélection, Paris.

2. Bodart, X.E., Curtat, M.R., and Fromy, P.G., "Computer Analysis of Smoke Protection of an Atrium Business Centre", in Fire Safety Science - Proceedings of the 3rd International Symposium, pp. 929940, Elsevier Applied Science, London and New York, 1991.

3. Bodart, X.E., "Analyse de sous-procédures réglementaires,...", 4 CSTB reports, July 1988.

4. DeCicco, P.R., "Life Safety Considerations in Atrium Buildings", SFPE Technology report 82-3, Boston (Massachussets), 1982.

5. Hansell, G.O., "Smoke Control in Atrium Buildings", Colt International (UK) Ltd, 1987.

6. Hansell, G.O., and Morgan,H.P., "Smoke Control in Atrium Buildings Using Depressurisation", 2 papers in Fire Science \& Technology, Vol. 10, No. 1 \& 2, 1990.

7. Morgan, H.P., and Hansell, G.O., "Atrium buildings: calculating smoke flows in atria for smoke control design", Fire Safety Journal, Vol. 12 No. 1, February 1987.

8. Chow, W.K., and Wong, W.K., "On the Simulation of Atrium Fire Environment in Hong-Kong Using Zone Models", Journal of Fire Sciences, Vol. 11 No. 1, Jan-Feb. 1993.

9. Chow, W.K., and Wong, W.K., "Application of the Zone Model FIRST...", Journal of Fire Sciences, Vol. 11, July-August 1993.

10. Note Technique No. 263, MI-DSC (Ministry of the Interior), 6 May 1987.

11. Bodart, X.E., and Curtat, M.R., "Risque d'enfumage du CNIT suite à un feu de boutique", CSTB report, April 1989.

12. Bodart, X.E., and Curtat, M.R., "Prediction of Entrained Mass Flows Through Vertical Openings In A Multiroom Fire Model", in Fire Safety Science - Proceedings of the 2nd International Symposium, pp. 917-926, Hemisphere Publishing Corporation, London, 1989.

13. Beyler, C.L., "Fire Plumes And Ceiling Jets", Fire Safety Journal, Vol. 11, No. 1 \& 2, July-Sept. 1986.

14. Bodart, X.E., Curtat, M.R., and Fromy, P.C., "Travaux CSTB en 89-90", CSTB/FIS Report, November 1990.

15. Bodart, X.E., "Calculs fondant le projet de nouvelles règles pour le désenfumage des atriums", CSTB/FIS Report, December 1992.

16. Hognon, B., "Mesure des quantités de chaleur, fumée,...", Cahier CSTB n² 2176, September 1987. 
